\title{
Probing depth origin of gravity anomalies in Taiwan through 3-D coherent velocity model
}

\author{
Yu-Tsung Lo ${ }^{1}$, Hsin-Hua Huang ${ }^{2}$, and Horng-Yuan Yen ${ }^{1, *}$ \\ ${ }^{1}$ Department of Earth Sciences, National Central University, Taoyuan City, Taiwan \\ ${ }^{2}$ Institute of Earth Sciences, Academia Sinica, Taipei City, Taiwan
}

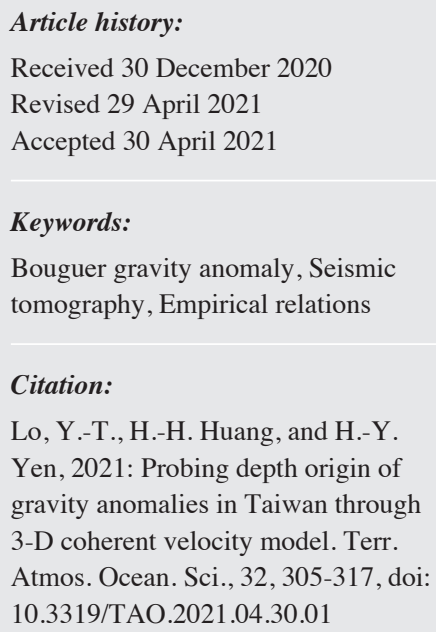

Citation:

Lo, Y.-T., H.-H. Huang, and H.-Y. Yen, 2021: Probing depth origin of gravity anomalies in Taiwan through 3-D coherent velocity model. Terr. Atmos. Ocean. Sci., 32, 305-317, doi: 10.3319/TAO.2021.04.30.01

\begin{abstract}
We constructed a 3-D coherent velocity model by extracting the common features from recent tomographic models and utilized the forward gravity modeling and wavelength filtering method to explore the depth origin of the gravity anomalies, such as the long-puzzling Puli Bouguer gravity low in west central Taiwan. The similarity analysis among the tomographic models shows the velocity structure most reliable in the depth range from 5 to $35 \mathrm{~km}$. Using empirical velocity-to-density relationships, we show that the calculated Bouguer gravity anomalies from the 3-D coherent velocity model could well reproduce the gravity observations in general. Through filtering process, we separated the Bouguer gravity anomalies into shallow $(0-17 \mathrm{~km})$ and deep gravity effects $(17-60 \mathrm{~km})$ for structural exploration. The results show that the shallow gravity effect mainly reflects the surface geological features with low gravity values for unconsolidated sediments in plain and foothill areas to the west and high values for exhumed metamorphic rocks in the mountainous areas to the east. The deep gravity effect reveals the lowest gravity anomalies located in central Taiwan beneath the western Central Range. The Puli Bouguer gravity low is likely a coincident feature arising from the mismatch of the shallow and deep gravity effects due to the N-S trending undulation of crustal thickness beneath the western plain/foothill. This crustal thickness undulation may be related to the rifting activity of Taihsi and Tainan basins in the past. Better discriminating the gravity effect from shallow and deep crust could help better understand the architecture and tectonic process of the Taiwan orogenic belt.
\end{abstract}

\section{INTRODUCTION}

Taiwan is located at the boundary between the Philippine Sea Plate (PSP) to the east and the Eurasian Plate (EP) to the west, with a convergence rate of $\sim 80 \mathrm{~mm} \mathrm{yr}^{-1}$ in a $\sim \mathrm{N} 118^{\circ} \mathrm{E}$ direction (Seno 1977; Yu et al. 1997). This plate boundary is complicated since it comprises two subduction zones with different subduction directions, where the EP subducts eastward beneath the PSP in the south and the PSP subducts northward beneath the EP in the east (Fig. 1). Various geophysical methods such as seismic tomography and gravity modeling has contributed long-term effort to investigate the complex subsurface structures of the Taiwan orogenic belt (Roecker et al. 1987; Yeh and Yen 1992; Rau and Wu 1995; Ma et al. 1996; Kim et al. 2005; Wang et al. 2006,

\footnotetext{
* Corresponding author

E-mail:yenhy@cc.ncu.edu.tw
}

2009; Wu et al. 2007, 2009; Yen and Hsieh 2010; Kuo-Chen et al. 2012; Huang et al. 2014a, b; Doo et al. 2016, 2018), yet the consistency among these methods and observations has not been achieved. For instance, the origin of the Puli gravity low in central Taiwan is still an unresolved debate (Huang et al. 2012). Also, with growing seismic data and the number of tomographic models, how similar or dissimilar between these models have not been investigated.

The first multicolor contoured version of the Bouguer anomaly map was published by Yeh and Yen (1992) and revised by Yen and Hsieh (2010). Figure 2 shows the updated map after Yen and Hsieh (2010). The isogals trend generally NNE-SSW in consistent with the structural trends of the orogenic belt. Negative gravity anomalies cover a major part of the island; positive anomalies mainly show in the eastern part of the Central Range, Coastal Range, and the northern 


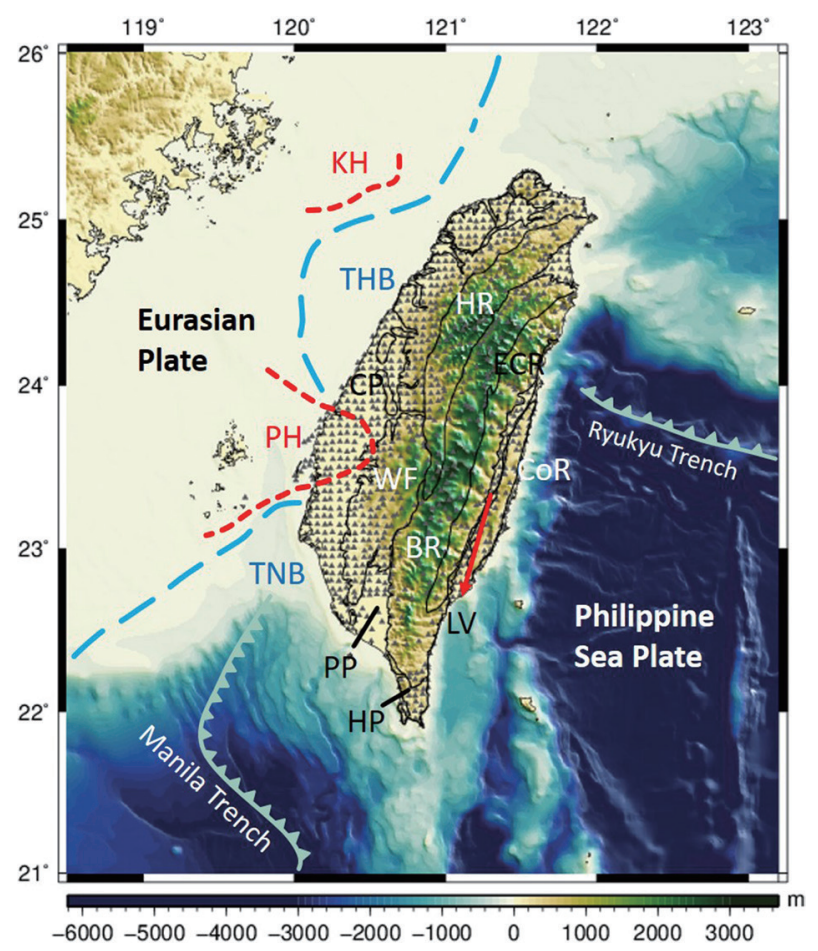

Fig. 1. Topography and geological subdivisions of the Taiwan region. CP: Coastal Plain; WF: Western Foothills; HR: Hsuehshan Range; BR: Backbone Range; ECR: Eastern Central Range; CoR: Coastal Range; LV: Longitudinal Valley; PH: Peikang High (a geometric basement high); KH: Kuanying High (a geometric basement high); PP: Pingtung Plain; HP: Hengchun Peninsula; THB: Taihsi Basin; TNB: Tainan Basin.

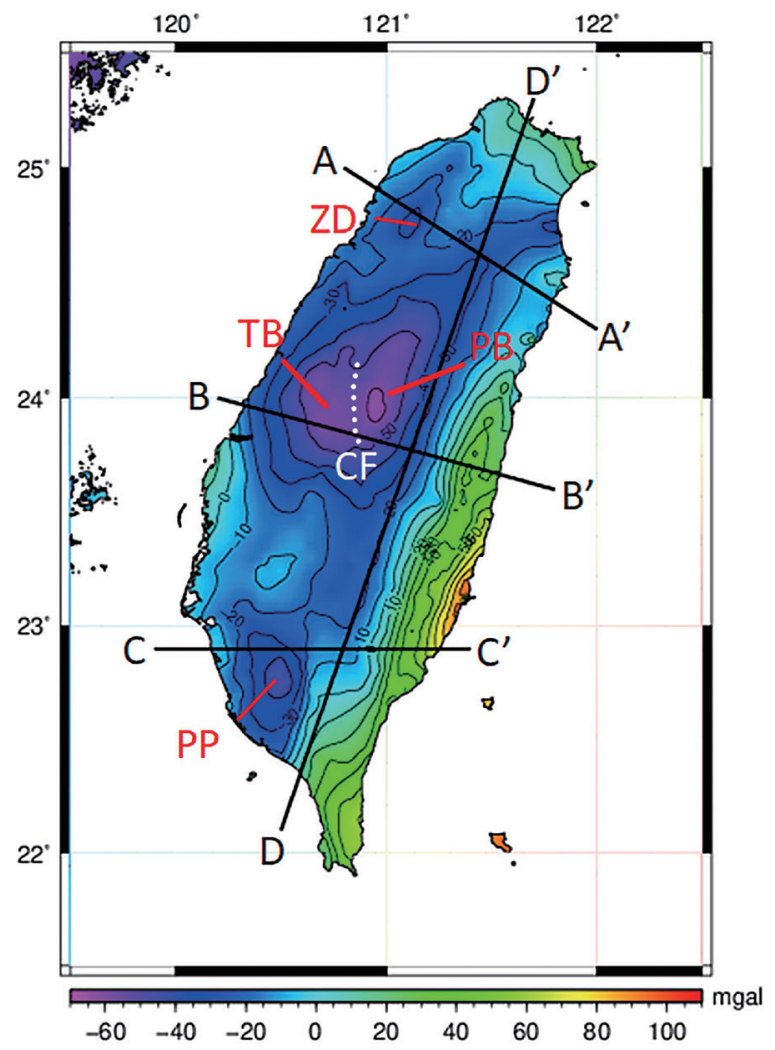

Fig. 2. The Bouguer gravity anomaly map of Taiwan. Black line: locations of density sections in Fig. 4. ZD: Zhudong gravity low; TB: Taichung basin gravity low; PB: Puli basin gravity low; PP: Pingtung Plain gravity low; CF: Chuchih Fault. 
end of the island. Two prominent Bouguer gravity lows are found in west central and southwestern Taiwan around Tertiary and Quaternary sedimentary basins, with lowest values of $-61 \mathrm{mGal}$ at the Puli basin of central Taiwan, so called Puli Bouguer gravity low. To cross-validate the consistency between the velocity models and the gravity observations, Yen and Hsieh (2010) examined three tomographic models (Rau and Wu 1995; Kim et al. 2005; Wu et al. 2007) by gravity forward modeling and found that the calculated gravity variations are not satisfactorily compatible with the observations, especially for the Puli gravity low and general overestimation at high elevation areas (>2000 m). This leads the authors to conclude that the shallow velocities are overestimated and the deep mountain root in the tested models should be shallower. Huang et al. (2012) showed that the island-wide ambient noise tomography with better resolution at shallow depths also fails to reproduce the Puli gravity low and hypothesized a deeper mountain root.

To tackle the velocity-gravity inconsistency with a different strategy, this study aimed to extract the coherent features from different tomographic models and explore the depth origin of the gravity anomalies using a wavelength filtering method. The Vp models of Kim et al. (2005), KuoChen et al. (2012), and Huang et al. (2014a) were used for the analysis in this study. The first model has been tested in Yen and Hsieh (2010) showing a better correlation with surface gravity observations; the latter two are the latest models using most up-to-date datasets from the TAIGER project and CWB seismic network. By analyzing the similarity among different models, we identified where the structures commonly exist and were likely reliable to establish a coherent velocity model. The forward calculated gravity field of the coherent velocity model was then compared with the observed gravity field to investigate the depth origin of gravity anomalies with a wavelength filtering method. Understanding whether the gravity anomalies arise from shallow or deep crust could give a better insight into the architecture and tectonic process of the Taiwan orogenic belt.

\section{DATA AND METHODOLOGY}

\subsection{Data}

Gravity observations and analysis are particularly useful as a reconnaissance tool for a large tectonic region. A high-resolution regional gravity map can help us understand its tectonic signatures. In this study, the gravity data were compiled from two sources: (1) 603 island-wide gravity stations that had been established by the Institute of Earth Sciences, Academia Sinica (Yen et al. 1995) since 1980, and (2) 3195 gravity stations that were chosen from the Ministry of the Interior (MOI). We closely follow the data processing of Yen and Hsieh (2010) to construct a Bouguer anomaly map (Fig. 2) after applying latitude, free-air, Bouguer, and terrain corrections. Bouguer and terrain correction were cor- rected with an average density of $2.57 \mathrm{~g} \mathrm{~cm}^{-3}$ (Yen et al. 1994) to eliminate gravity effect of surface rocks above the sea level. The updated Bouguer anomaly map here is in general similar to the one published by Yen and Hsieh (2010). More gravity observation control points in mountainous and plain areas included were mainly helpful for revealing more short-wavelength details of gravity anomalies caused by shallow structures and for increasing data points of forward modeling the coherent velocity model.

\subsection{Coherent Velocity Model}

To bypass the inconsistency issue between velocity models, we reconstruct a new velocity model that capture the coherent features in the three $\mathrm{Vp}$ models via statistic approach. The model area extended $100 \mathrm{~km}$ outward from the surface gravity observations in four directions, where all three velocity models were re-gridded into the same grids using tri-linear interpolation. The model grid size was set to $1 \times 1 \times 1 \mathrm{~km}^{3}$ to avoid discrepancy in selecting grid points during calculation. The mean and standard deviation of $\mathrm{Vp}$ for each grid point were then calculated. Figure 3 shows the distribution of standard deviations at each grid and a clear knick point is observed around 0.3. We thus used 0.3 as a threshold and only calculate mean velocity for the grids with a standard deviation of less than $0.3 \mathrm{~km} \mathrm{~s}^{-1}$ to construct new coherent velocity model. For the girds with a standard deviation larger than $0.3 \mathrm{~km} \mathrm{~s}^{-1}$ as the blank areas present in Fig. 4, we linearly interpolated their velocity values from nearby coherent grid points with standard deviations smaller than $0.3 \mathrm{~km} \mathrm{~s}^{-1}$. For the areas outside of the velocity models, the nearest-neighbor interpolation method was used to fill in smoothly-varying velocity values to avoid generating false gravity signals at the model boundaries.

\subsection{Bouguer Gravity Calculation}

The conversion from the coherent velocity model to gravity observation can be achieved by using empirical formula between velocity and density. As different empirical formulas may result in differences in calculation results, two empirical formulas were used and compared as follows: (1) Suzuki (1980) empirical relationship formula:

$\rho=0.8+0.3 * V_{p}$

(2) Brocher (2005) empirical relationship formula:

$$
\begin{aligned}
\rho= & 1.6612 V_{p}-0.4721 V_{p}^{2}+0.0671 V_{p}^{3}- \\
& 0.0043 V_{p}^{4}+0.000106 V_{p}^{5}
\end{aligned}
$$

After converting the velocity to density at each grid 


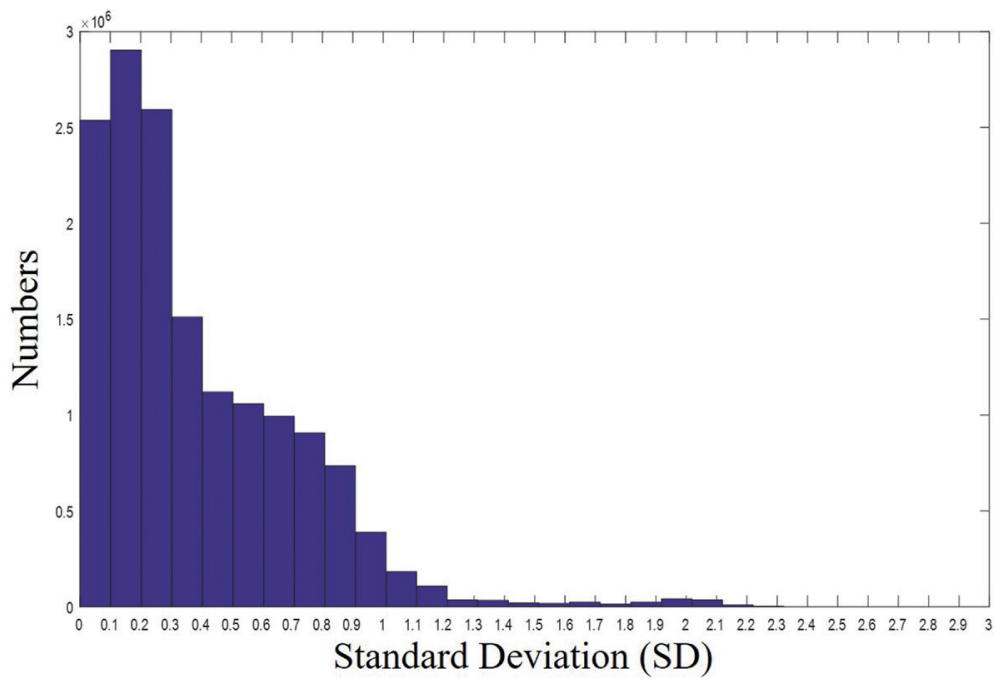

Fig. 3 Distribution of standard deviations at each interpolated grid between three velocity models used.
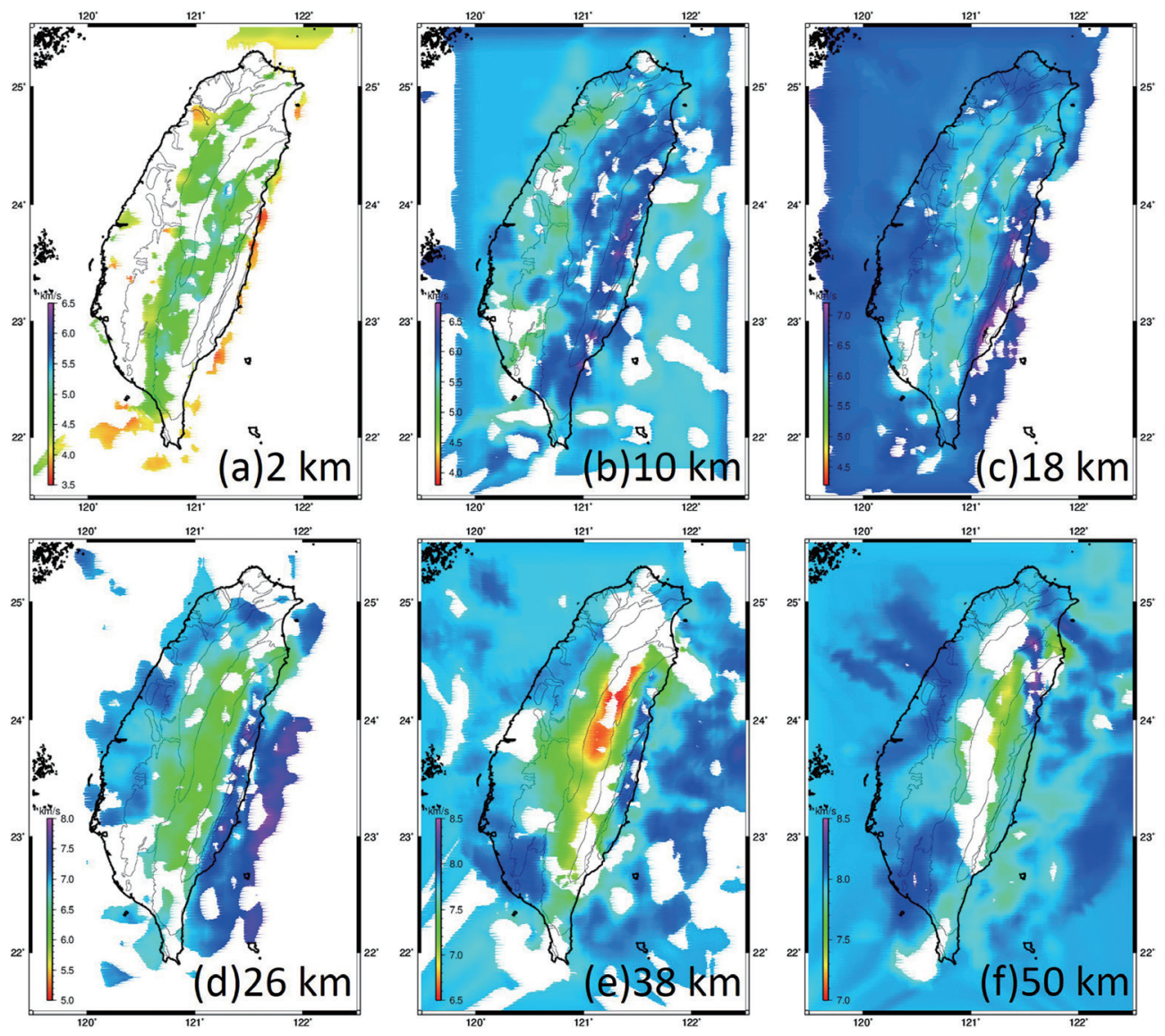

Fig. 4. Different depth slices of the 3-D coherent velocity model. 
of velocity models, we forward calculated the gravity field with converted density models. The gravitational effect $\left(g_{i j}\right)$ at the ith gravity station from a certain density block, $\mathrm{j}$, can be represented as

$g_{i j}=\rho_{j} G\left[\frac{Z_{j} d x d y d z}{R_{i j}{ }^{3}}\right]$

where $\rho_{j}$ is the density contrast of a certain block, $j, G$ is the gravitational constant, $Z_{j}$ is the depth of certain block, $j$, and $R_{i j}$ is the distance between the gravity station, $i$, and a certain block, $j$. The forward Bouguer anomaly $\left(g_{i}\right)$ created by the initial density model at the ith gravity station is

$g_{i}=\sum_{j=1}^{n} g_{i j}=\sum_{j=1}^{n} \rho_{j} G\left[\frac{Z_{j} d x d y d z}{R_{i j}{ }^{3}}\right]$

where $n$ is the total number of model blocks and $\rho_{j}$ is the density contrast of each block. Then, the Bouguer anomaly distributions could be obtained by summing the gravitational effect from each block, $g_{i j}$.

\subsection{Wavelength Filtering Method}

Wavelength filtering method is further applied to identify contour trends at various cut-off wavelengths and probe the depth origins of main regional negative and positive gravity anomalies. As Bouguer anomalies are the integral effect of subsurface density structure, the short- and longwavelength variations are caused by the shallow and deep density structure theoretically. The origin depths of the anomalies could therefore be estimated by using the 3-D approximation relationship between the maximum depth of a causative body $\left(Z_{S}\right)$ and a certain cut-off wavelength $\left(\lambda_{C}\right)$ given by Jung (1961) as

$\lambda_{C} \geq 3 Z_{S}$

where using different cut-off wavelength, we could get the gravity effect at different depth ranges.

By establishing a coherent velocity model and calculating its theoretical gravity anomaly, the residual gravity anomalies as the difference between calculated and observed values were obtained. We can then use the wavelength filtering method in the same way to divide the residual gravity anomalies into the shallow and deep depth ranges and correct the calculated values of the coherent velocity model. Finally, an integrated shallow and deep gravity anomaly based on the velocity structure was obtained.

\section{RESULTS AND DISCUSSION}

\subsection{3-D Coherent Velocity Model}

In order to calculate the gravity values from the most reliable velocity structures, we extracted the coherent values from the three velocity models of Kim et al. (2005), KuoChen et al. (2012), and Huang et al. (2014a). Figure 4 shows the results of extracted coherent velocity model at different depths. The white area indicates that the standard deviation of the velocity values from the three models is greater than $0.3 \mathrm{~km} \mathrm{~s}^{-1}$, indicating relatively incoherent values.

At the depth of top $2 \mathrm{~km}$, the velocity models are rather inconsistent because of the worse resolution of body-wave tomography at shallow depths. The logging velocity constraints included in the Huang et al. (2014a) also contribute to the large deviation from the other two models (Fig. 4a). At depths of 3 to $21 \mathrm{~km}$, the three models become more consistent but with sporadic distribution of large velocity standard deviations in the land area and east offshore (Figs. 4b and c). At the depths of 22 to $35 \mathrm{~km}$, larger velocity standard deviation areas are mostly located in the southwestern and northern Taiwan (Fig. 4d); below the depth of $38 \mathrm{~km}$, the large velocity standard deviation mainly appears beneath the Central Range (Figs. 4e and f). This may result from less and relatively sparse ray distribution due to only shallow seismicity occurring in the Central Range and also different datasets used in the three models. Note that we also extract coherent values from the three models in the offshore areas as shown at the depths 10,38 , and $50 \mathrm{~km}$. This may result from similar velocity values in 1-D initial models used in the three models. However, since the velocity variations are small and mostly 1-D in these offshore areas so it contributes little to the forward calculated gravity anomalies. The depth slices from 0 to $60 \mathrm{~km}$ of the 3-D coherent velocity model are shown in Figs. S1 and S2 for reference.

We selected four cross sections to discuss the lateral variations in the coherent velocity model with three $\mathrm{E}-\mathrm{W}$ profiles from south to north and one N-S profile running through the Central Range. Both the mean velocity and standard deviation are shown in Fig. 5. Using the Vp of $5.2 \mathrm{~km} \mathrm{~s}^{-1}$ as a reference velocity of the interface between the sedimentary and basement rocks (Camanni et al. 2016; Brown et al. 2017). The sedimentary layer is thickest covering the western plain and gradually thinning out toward the mountain areas in all three E-W cross sections. On the other hand, $\mathrm{Vp}$ of $7.5 \mathrm{~km} \mathrm{~s}^{-1}$ has been suggested to represent the Moho interface in the Taiwan region (Kuo-Chen et al. 2012). With that, we see the Moho variations are gentle in the northern Taiwan and thicken in the central and northern Taiwan. This crustal thickening results from the collision between the Eurasian Plate and Philippine Sea Plate (Wu et al. 1997). From standard deviation cross sections, the most 

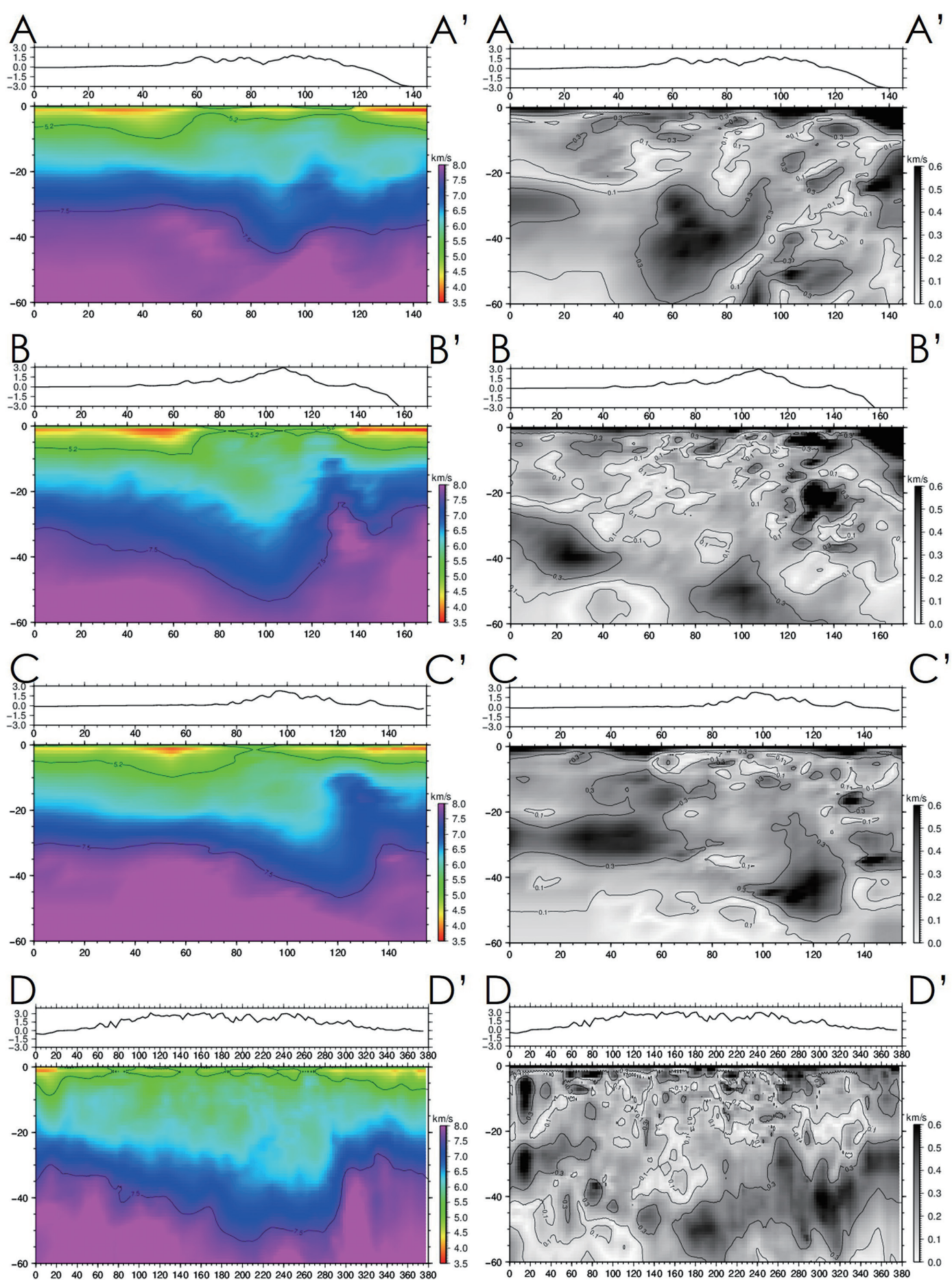

Fig. 5. Four selected cross sections of P-wave velocity (left) and standard deviation (right) from the coherent velocity model. Back lines indicate the velocity contours at 5.2 and $7.5 \mathrm{~km} \mathrm{~s}^{-1}$. The locations of the cross sections are shown in Fig. 2. 
coherent parts between the three models mainly lies at a depth of 5 to $35 \mathrm{~km}$ beneath the Taiwan island, except for the Longitudinal Valley region. There are still notable discrepancies in the deep structures below $25 \mathrm{~km}$ in the western and below $35-40 \mathrm{~km}$ in the central Taiwan.

\subsection{Calculated Bouguer Anomaly}

For gravity forward calculation, we tested two relationships of Suzuki's (1980) and Brocher's (2005) using the coherent velocity model without and with $10 \%$ random velocity perturbations. The results of the forward calculation are shown in Fig. 6. The trends in the four cases are similar, where the random velocity perturbations, representing velocity inaccuracy, do not influence the overall pattern much (Figs. $6 \mathrm{~b}$ and d). Because the relationships of Brocher's and Suzuki's are obviously different in the lowvelocity part, the difference of forward calculation results mainly appears in the plains and basins (Figs. 6a and c). The main differences appear in the Puli gravity low area in the central part of Taiwan and the Pingtung Plain gravity low area in the southwest, where the low-density materials (i.e., low-velocity anomalies) are widely distributed at shallow depths. The correlation coefficients between the calculated and the observed gravity values of four velocity-to-density cases are $0.6803,0.6779,0.7400$, and 0.7335 . The forward calculation results using Suzuki's relationship are closer to the observed gravity data so we adopt Suzuki's relationship for the later analysis. In Fig. 6c, it shows the Puli gravity low and reproduces most of the features in the observed gravity anomalies in Fig. 2. The forward calculations for the individual three models are also shown in Fig. S3 for reference. We also note that adding large $10 \%$ random velocity errors only cause relatively minor effect on the final results. Factors that cause velocity anomalies (such as pressure and temperature) usually result in velocity variations of $2-3 \%$ (Huang et al. 2015a), which should be much lower than the $10 \%$ test value.

The gravity residuals which were calculated by subtracting the theoretical forward values from the observed Bouguer gravity values (Fig. 2) are shown in Fig. 7. The residuals range from -40 to $40 \mathrm{mGal}$ for the Brocher's and Suzuki's relationship, the results of Suzuki are more concentrated on the residual of $0 \mathrm{mGal}$. The negative residuals mainly exist in the Western Plains while the positive residuals appear in the Central Range, eastern and southernmost Taiwan. The negative residuals indicate that the observed values are smaller than the calculated values, probably because the density model values in the area are still greater than the actual values; positive residuals are vice versa. The source of the Bouguer anomaly differences could possibly result from the inaccuracy of the velocity model and velocity-to-density relationship, as well as the interpola- tion method used. However, the extracted coherent velocity model has already captured the general pattern of the Bouguer gravity anomalies and shows better fitting than the previous models do (Yen and Hsieh 2010).

\subsection{Gravity Effect of the Upper and Lower Crust}

Figure 8 shows the procedure of separating the gravity effect results from the shallow and deep structures. The whole process decomposes the observed Bouguer anomaly into the calculated gravity anomaly of coherent model and the residual gravity anomaly when subtracting the calculated anomaly from the observed one (model discrepancy). The calculated gravity anomaly and residual gravity anomaly are then divided into shallow and deep effects through the methods of forward calculation and wavelength filtering analysis separately. Finally, the shallow and deep calculated and residual gravity anomalies then add back to obtain the integral shallow and deep gravity anomalies, respectively. Forward gravity modeling allows us to calculate the gravity effects from the shallow and deep parts of the model separately. The calculation results would be mainly affected by trend changes of lateral velocity variations. According to the retrieved coherent velocity model results (Figs. 4 and 5), the $17 \mathrm{~km}$ depth seems to be a depth at which the main trend of velocity variations changes. Shallower than $17 \mathrm{~km}$ depth, the velocity of the Western Plain is relatively slow compared to that of the mountain areas because of the contrast between the sedimentary rocks vs. metamorphic rocks; Deeper than $17 \mathrm{~km}$ depth, the velocity contrast reverses because of the crustal thickening beneath mountain areas. In order to ensure that the shallow and deep gravity anomaly effects will not cancel out by opposite tends in velocity distribution, the depth of $17 \mathrm{~km}$ is chosen as a boundary to better separate the gravity effects from the shallow and deep structures where the trend of velocity distribution is transformed. The coherent velocity model is then divided into the shallow (0 to $17 \mathrm{~km}$ ) and deep layers (17 to $60 \mathrm{~km}$ ) to forward calculate the gravity anomalies in Figs. 9a and c, respectively.

Simultaneously, the residual gravity variations (Fig. 7) can be divided into long and short wavelength gravity anomaly after wavelength filter processing (Jung 1961). The longwavelength residual gravity is considered to be due to deep structural discrepancies, and the short-wavelength gravity effect is considered to be due to shallow structural discrepancies (Figs. 9b and d). Then, the residual gravity values of the shallow part (0 to $17 \mathrm{~km}$ ) and the deep part (17 to $60 \mathrm{~km}$ ) after filter processing were added to the forward calculated gravity results (Figs. 9a and c), respectively, to obtain final integral gravity variations resulting from shallow and deep structures separately (Fig. 10). Note that the summation of the integral shallow and deep gravity anomalies would be equal to the observed Bouguer anomalies in principle. 


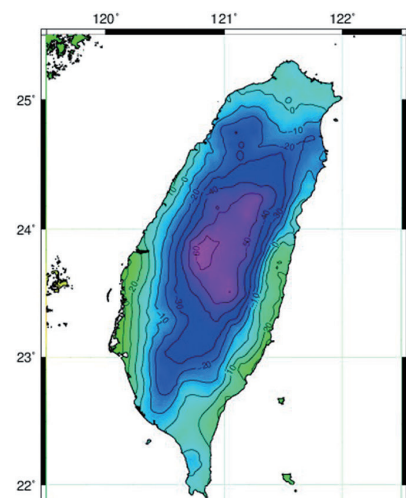

(a)

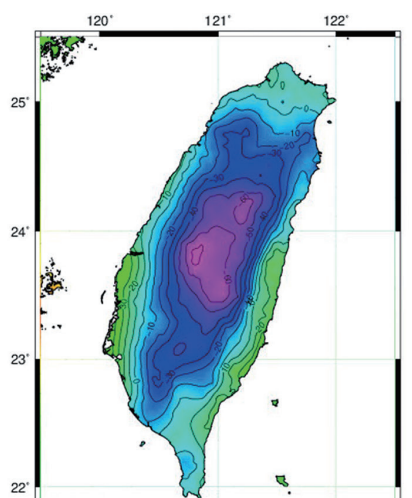

(b)

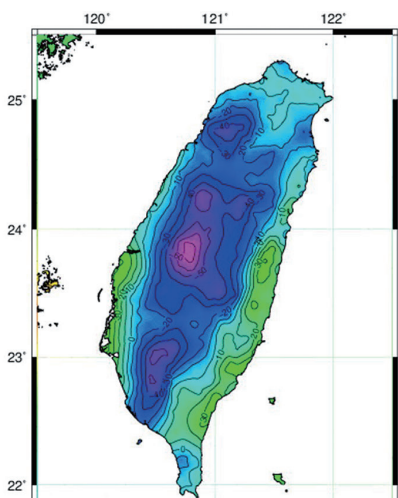

(c)

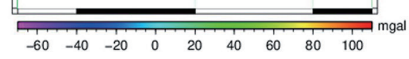

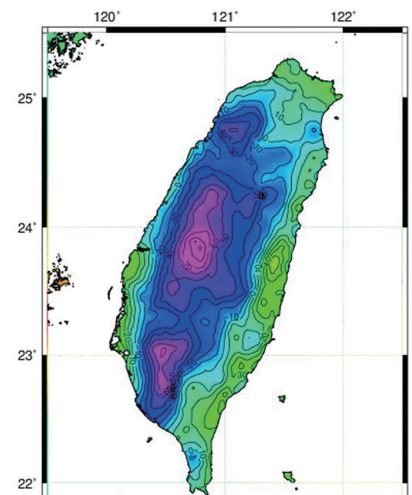

(d)

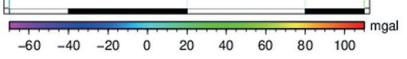

\begin{tabular}{llllllllllll}
\hline \hline-60 & -40 & -20 & 0 & 20 & 40 & 60 & 80 & 100
\end{tabular} mgal

Fig. 6. The Bouguer anomaly distribution calculated from coherent velocity model converted with different relationship formulas. (a) Brocher (2005), (b) Brocher (2005) with Vp model adds 10\% random disturbance, (c) Suzuki (1980), (d) Suzuki (1980) with Vp model adds 10\% random disturbance.

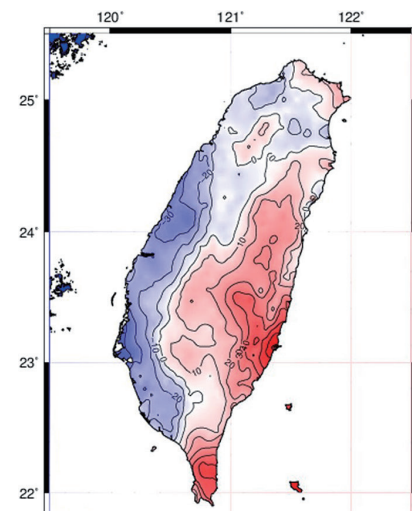

(a)
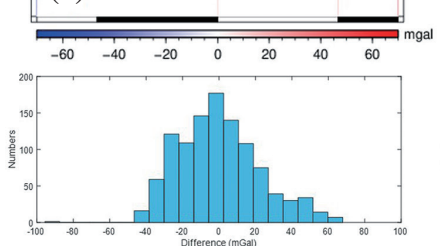

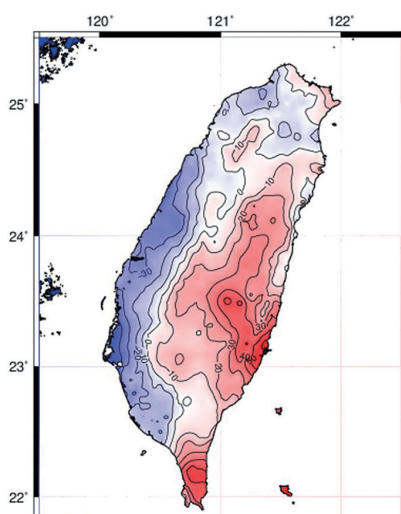

(b)
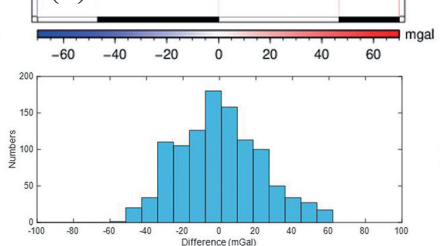

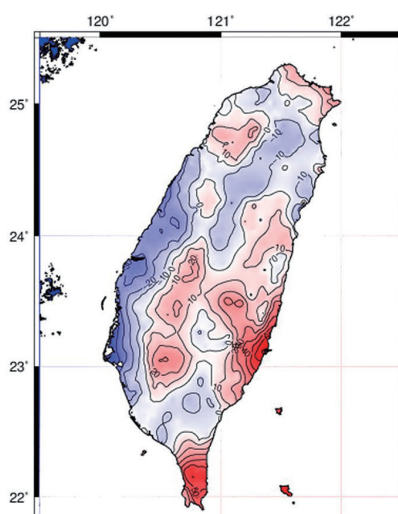

(c)

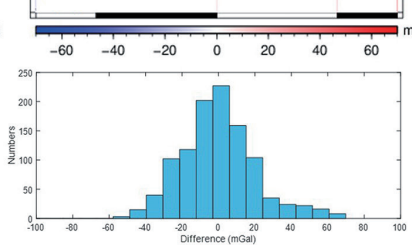

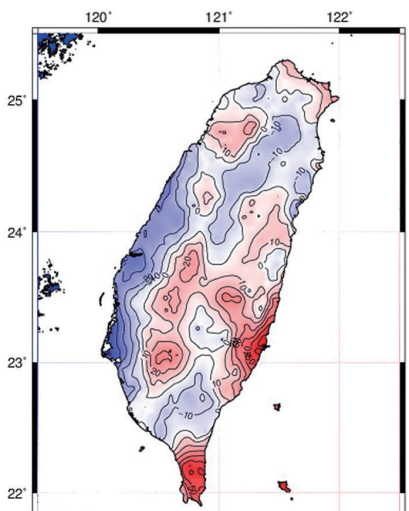

(d)

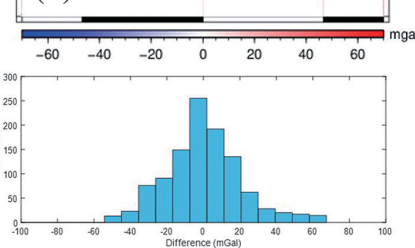

Fig. 7. The distribution and histogram of Bouguer anomaly differences between calculated model and the observed gravity data tabulated by the number of gravity stations. (a) Brocher (2005), (b) Brocher (2005) with Vp model adds 10\% random disturbance, (c) Suzuki (1980), (d) Suzuki (1980) with Vp model adds 10\% random disturbance.

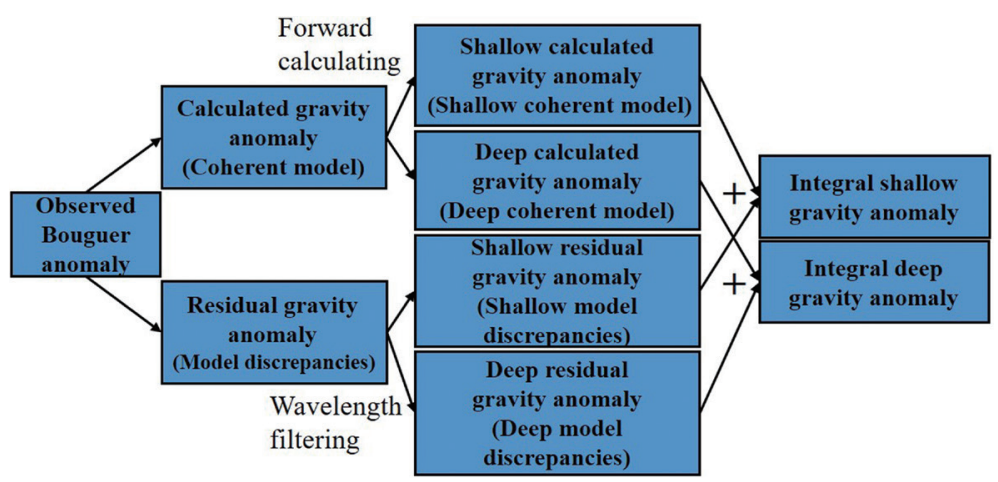

Fig. 8. Workflow for separating the deep and shallow gravity effect. 


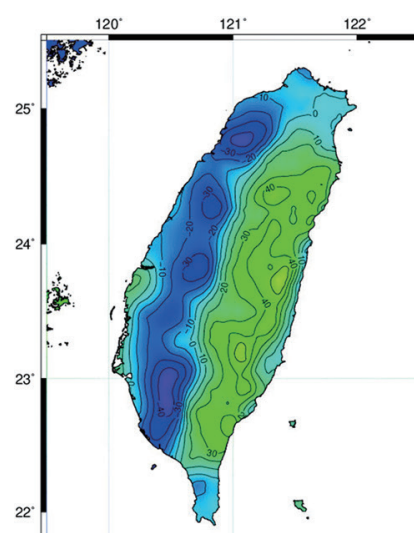

(a)
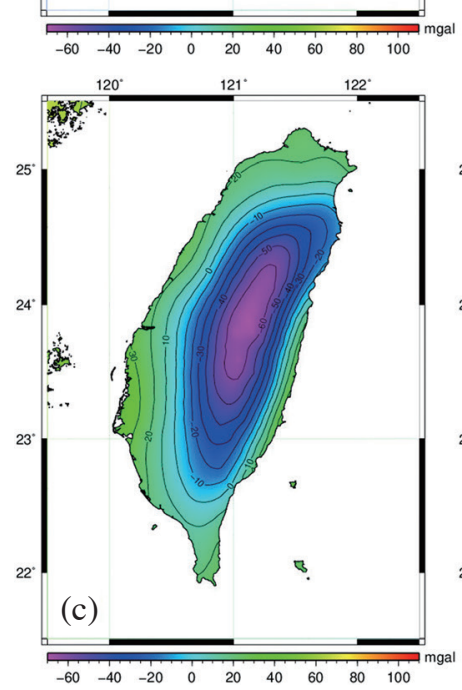

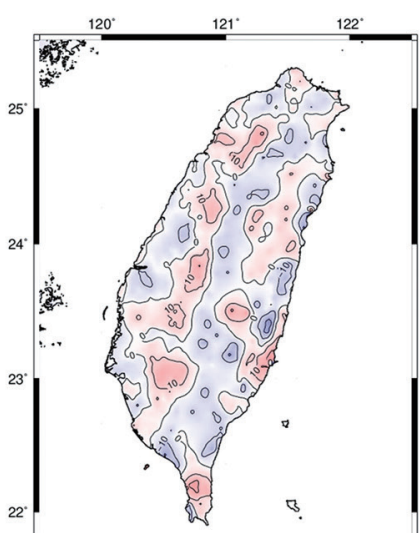

(b)
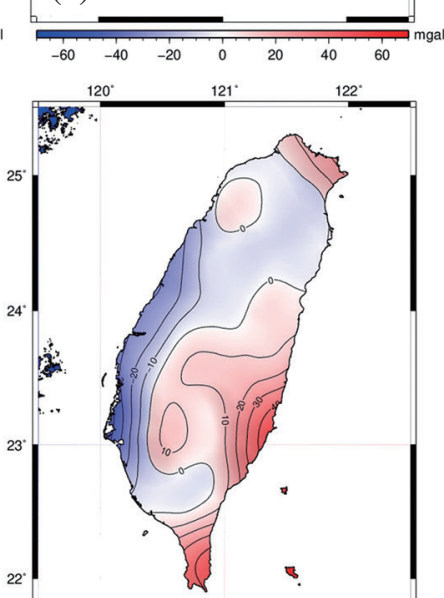

(d)

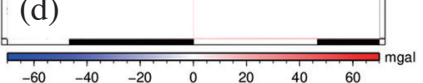

Fig. 9. Gravity effect from the shallow $(0-17 \mathrm{~km})$ and deep structure $(17-60 \mathrm{~km})$. (a) Calculated gravity anomalies and (b) filtered gravity residuals from shallow structure. (c) Calculated gravity anomalies and (d) filtered gravity residuals from deep structure.

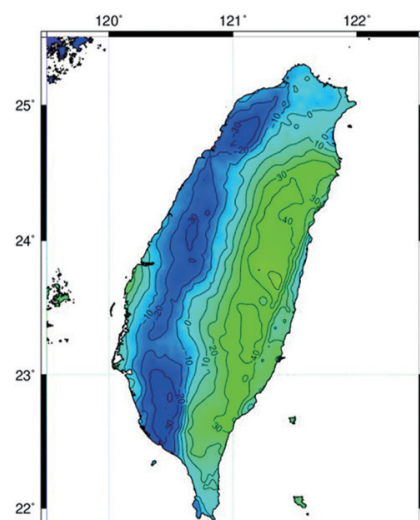

(a)

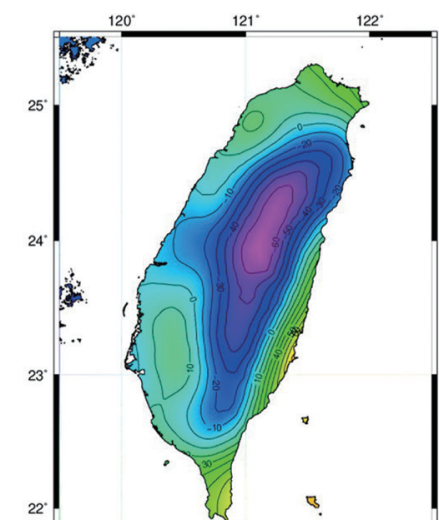

(b)
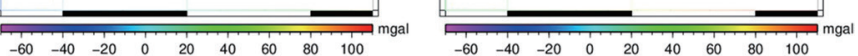

Fig. 10. Integral shallow and deep gravity anomaly of coherent velocity-to-density model. 
The distribution of integral shallow gravity values shows a good fit to the surface geological units (Fig. 10a). The high gravity anomalies in the mountainous areas mainly reflect the exhumed metamorphic rocks with high Vp and Vs in the upper crust presented in the body-wave tomography and ambient noise tomography studies (Kim et al. 2005; Kuo-Chen et al. 2012; Huang et al. 2014a, 2015b). The low gravity anomalies in the western plain area are then well correlated to several sedimentary basins with low $\mathrm{Vp}$ and Vs. Usually the lower gravity anomaly is interpreted as the accumulation of low-density material at shallow depths and as the thickening of the crust at the deep depths.

For the integral deep gravity values (Fig. 10b), the areas with the lowest deep gravity anomaly is located in the middle of Taiwan and is considered to be the thickest crust. The deepest Moho was also found to be deepest of $53 \mathrm{~km}$ in the central Taiwan from teleseismic receiver functions (Wang et al. 2010). The general variations of the crustal thickness are also similar to the Moho variations extracted by $\mathrm{Vp}$ of $7.5 \mathrm{~km} \mathrm{~s}^{-1}$ in tomographic models (Kuo-Chen et al. 2012; Huang et al. 2014a) and by a density of $3.2 \mathrm{~g} \mathrm{~cm}^{-3}$ from the 3-D density model of Hsieh and Yen (2016). It is worthy to note that the deep gravity anomalies (Fig. 10b) are not only N-S extending but slightly convex to the west in central Taiwan, which is probably related to the Tainan and Taihsi basins to the southwest and northwest where the crust should have been extended to be thinner due to rifting activity in the past (Lin and Watts 2002; Lin et al. 2003). The high gradient from the Central Range to the Hengchun Peninsula and the Longitudinal Valley may reflect the entering to the oceanic plates.

Three cross-sections were selected to compare the observed Bouguer gravity anomalies and the integral gravity anomalies from the shallow and deep structures and discuss their discrepancies and depth origin in detail (Fig. 11). Crosssection AA' cuts through the Western Foothills, Hsuehshan Range, and the northern Backbone Range from west to east. The integral shallow gravity values reach its minimum around $-38 \mathrm{mGal}$ at Zhudong (ZD) and gradually increase to 30 mGal across the Hsuehshan Range and Central Range. In Contrast, the integral deep gravity values show an opposite trend that peak at $\sim 20 \mathrm{mGal}$ around Zhudong and gradually decreases to $-40 \mathrm{mGal}$ eastward. The observed Bouguer gravity anomalies then show a much minor variation from -20 to $-10 \mathrm{mGal}$ as the opposite trends of the shallow and deep gravity effects compensate to each other. This is a clear example that interpretations based on surface Bouguer gravity variations with constant crustal density assumed can sometimes be biased and should be taken with caution.

Cross-section BB' runs through the debating Puli Bouguer anomaly low in the west central Taiwan. For the integral shallow gravity effect, the gravity low is spatially well correlated to the Taichung and Puli Basin (TB and PB, Fig. 2). The low gravity values mainly result from more than $5000 \mathrm{~m}$ of Neogene sedimentary rock in the basins of the western plain and foothill (Sun 1982). However, unlike the cross-section AA', the observed Bouguer gravity values (Gray dashed curve) remain negative across most of the Central Range where denser, lightly metamorphosed Paleogene sandstone and slate have been exposed (Yen et al. 1998). This is because the integral deep gravity anomalies seem to shift a bit westward with anomalously low values present beneath the eastern part of the western foothill (blue curve). This westward shift of the deep structure can be seen in Fig. 10b where a lateral convex of low gravity values to the west in the central Taiwan and thus makes the gravity effects from shallow and deep structure do not well compensate each other as in Cross-section AA'. The peak of highest negative anomalies for integral deep gravity anomalies and observed Bouguer gravity anomalies are therefore inconsistent and have been long debated in the past (Yen et al. 1998; Hsieh and Yen 2016).

Cross-section CC' runs from the Pingtung Plain to the southern end of the Longitudinal Valley where the highest Bouguer anomaly values present on the island (Fig. 2). The integral shallow gravity effect shows lowest values of $-38 \mathrm{mGal}$ in the Pingtung Plain. The gravity low is likely caused by the thick sedimentary layer or deeper basement with a depth up to $9 \mathrm{~km}$ (Yu and Tsai 1981). The lowest values of the integral deep gravity effect are below the central mountain range, reaching about $-30 \mathrm{mGal}$. The variations of the integral shallow and deep gravity effects are similar to those in Cross-section $\mathrm{AA}^{\prime}$ and better compensate to each other than Cross-section BB'.

In summary, by separating the gravity effects from the shallow and deep structure, we can see consistent eastward crustal thickening with the deepest mountain root located beneath the western Central Range from north to south (Cross-sections AA'-CC', Fig. 11), which is in a good agreement with the previous seismic experiment study (Kuo et al. 2016). The shallow structure mainly shows low and high gravity anomalies in the western plain/foothill and mountain areas that well reflect the thick sediments and exhumed metamorphic rocks (Fig. 10a). However, the NS-trending undulation of the crust thickness beneath the western foothill seems the key to result in the long-puzzling Puli Bouguer gravity low in west central Taiwan (Fig. 2) as a consequence of combined gravity effects from offset shallow and deep structures, not a deep mountain root (Cross-section BB', Fig. 11). The observed surface Bouguer gravity is the combined effect of the shallow and deep structures that could sometimes produce misleading features as the Puli gravity low. The traditional gravity simulation method directly estimating the crustal thickness assuming constant crustal density from the Bouguer gravity anomalies may therefore obtain the biased thickness of the crust. Multidisciplinary geophysical analysis such as combing the seismic velocity model and gravity data could potentially diminish this bias. 

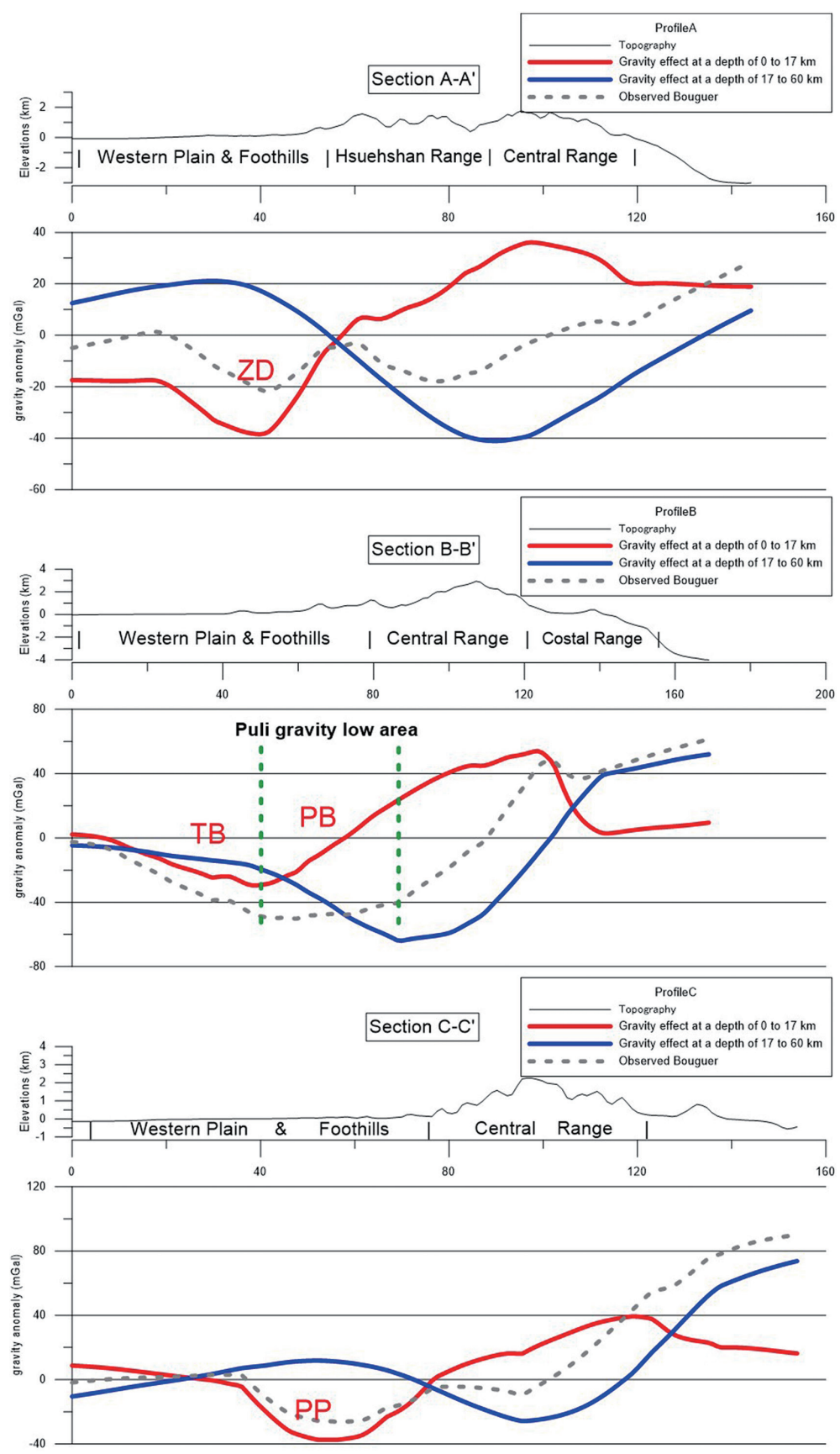

Fig. 11. Three section slices of integral shallow and deep gravity variation from coherent velocity-to-density model. The locations of the sections are shown in Fig. 2. 
It should be noted that while the variations in rock composition should naturally be accounted for by the lateral variations of 3-D velocity model, the relatively large velocity uncertainty at shallow depths could exist in body-wave tomography. But we expect that such uncertainty will mainly produce short wavelength anomalies in integral shallow gravity effect and will not affect the interpretations of combined shallow and deep gravity effects in general.

\section{CONCLUSIONS}

This study extracted the coherent features from three recent tomographic models (Kim et al. 2005; Kuo-Chen et al. 2012; Huang et al. 2014a) and utilized the forward gravity modeling and wavelength filtering method to explore the depth origin of the gravity anomalies. By separating and comparing the integral gravity effects from shallow and deep structures, we found that for shallow structure, the Bouguer gravity effect mainly corresponds to the surface geological features. The relatively high gravity anomaly appears in the mountainous areas; the plain and foothill areas are shown with relatively low gravity values that clearly describe several sedimentary basins (Fig. 10a). For deeper structure, the areas with the lowest deep gravity anomalies located in the central Taiwan beneath the western Central Range is considered to be the thickest crust (Fig. 10b). Most importantly, we showed the long-debating Puli Bouguer gravity low could possibly be an artifact feature arising from the mismatch of the shallow and deep gravity effects due to the N-S trending undulation of crustal thickness beneath the western plain/foothill (Fig. 11). This crustal thickness undulation may be related to the Taihsi and Tainan rifting basins to the northwest and southwest, respectively (Fig. 10b).

The similarity analysis between the different velocity models found that the most reliable velocity structures, although spatially varied, are in the upper and middle crust from 5 to $35 \mathrm{~km}$ depth in general (Figs. 4 and 5). Further improvements in resolving better velocity structures at the uppermost and deeper crust are still needed. Actual subsurface structures need to be compatible with different geophysical observations. Our analysis here demonstrates possible biased from interpreting one certain dataset and encourage multidisciplinary geophysical analysis such as gravity and travel time data for cross validation, which will further our understanding to the orogenic architecture and tectonic process of Taiwan on the way.

Acknowledgements We thank the Institute of Earth Sciences, Academia Sinica and Ministry of the Interior for kindly providing the data for this integrated work and very thank three reviewers who significantly improve and refine the manuscript. This work was supported by a Postdoctoral funding support from the Ministry of Science and Technology, Taiwan (MOST 109-2811-M-008-521).

\section{REFERENCES}

Brocher, T. M., 2005: Empirical relations between elastic wavespeeds and density in the Earth's crust. Bull. Seismol. Soc. Am., 95, 2081-2092, doi: 10.1785/0120050077. [Link]

Brown, D., J. Alvarez-Marron, C. Biete, H. Kuo-Chen, G. Camanni, and C.-W. Ho, 2017: How the structural architecture of the Eurasian continental margin affects the structure, seismicity, and topography of the south central Taiwan fold-and-thrust belt. Tectonics, 36, 1275-1294, doi: 10.1002/2017TC004475. [Link]

Camanni, G., J. Alvarez-Marron, D. Brown, C. Ayala, Y.M. Wu, and H.-H. Hsieh, 2016: The deep structure of south-central Taiwan illuminated by seismic tomography and earthquake hypocenter data. Tectonophysics, 679, 235-245, doi: 10.1016/j.tecto.2015.09.016. [Link]

Doo, W.-B., H. Kuo-Chen, D. Brown, C.-L. Lo, S.-K. Hsu, and Y.-S. Huang, 2016: Serpentinization of the forearc mantle along the Taiwan arc-continent collision of the northern Manila subduction zone inferred from gravity modeling. Tectonophysics, 691, 282-289, doi: 10.1016/j.tecto.2016.10.019. [Link]

Doo, W.-B., C.-L. Lo, S.-K. Hsu, C.-H. Tsai, Y.-S. Huang, H.-F. Wang, S.-D. Chiu, Y.-F. Ma, and C.-W. Liang, 2018: New gravity anomaly map of Taiwan and its surrounding regions with some tectonic interpretations. J. Asian Earth Sci., 154, 93-100, doi: 10.1016/j. jseaes.2017.12.010. [Link]

Hsieh, H.-H. and H.-Y. Yen, 2016: Three-dimensional density structures of Taiwan and tectonic implications based on the analysis of gravity data. J. Asian Earth Sci., 124, 247-259, doi: 10.1016/j.jseaes.2016.05.009. [Link]

Huang, H.-H., Y.-M. Wu, X. Song, C.-H. Chang, S.-J. Lee, T.-M. Chang, and H.-H. Hsieh, 2014a: Joint Vp and Vs tomography of Taiwan: Implications for subductioncollision orogeny. Earth Planet. Sci. Lett., 392, 177191, doi: 10.1016/j.eps1.2014.02.026. [Link]

Huang, H.-H., Y.-M. Wu, X. Song, C.-H. Chang, H. KuoChen, and S.-J. Lee, 2014b: Investigating the lithospheric velocity structures beneath the Taiwan region by nonlinear joint inversion of local and teleseismic $\mathrm{P}$ wave data: Slab continuity and deflection. Geophys. Res.Lett.,41,6350-6357, doi: 10.1002/2014GL061115. [Link]

Huang, H.-H., F.-C. Lin, B. Schmandt, J. Farrell, R. B. Smith, and V. C. Tsai, 2015a: The Yellowstone magmatic system from the mantle plume to the upper crust. Science, 348, 773-776, doi: 10.1126/science.aaa5648. [Link]

Huang, T.-Y., Y. Gung, W.-T. Liang, L.-Y. Chiao, and L. S. Teng, 2012: Broad-band Rayleigh wave tomography of Taiwan and its implications on gravity 
anomalies. Geophys. Res. Lett., 39, L05305, doi: 10.1029/2011GL050727. [Link]

Huang, T.-Y., Y. Gung, B.-Y. Kuo, L.-Y. Chiao, and Y.N. Chen, 2015b: Layered deformation in the Taiwan orogen. Science, 349, 720-723, doi: 10.1126/science. aab1879. [Link]

Jung, K., 1961: Schwerkraftverfahren in Der Angewandten Geophysik, Akademische Verlagsgesellschaft Geest \& Portig, Leipzig, 362 pp.

Kim, K.-H., J.-M. Chiu, J. Pujol, K.-C. Chen, B.-S. Huang, Y.-H. Yeh, and P. Shen, 2005: Three-dimensional $V_{P}$ and $V_{S}$ structural models associated with the active subduction and collision tectonics in the Taiwan region. Geophys. J. Int., 162, 204-220, doi: 10.1111/j.1365246x.2005.02657.x. [Link]

Kuo, Y.-W., C.-Y. Wang, H. Kuo-Chen, X. Jin, H.-T. Cai, J.-Y. Lin, F. T. Wu, H.-Y. Yen, B.-S. Huang, W .-T. Liang, D. Okaya, and L. Brown, 2016: Crustal structures from the Wuyi-Yunkai orogen to the Taiwan orogen: The onshore-offshore wide-angle seismic experiments of the TAIGER and ATSEE projects. Tectonophysics, 692, 164-180, doi: 10.1016/j.tecto.2015.09.014. [Link]

Kuo-Chen, H., F. T. Wu, and S. W. Roecker, 2012: Threedimensional $\mathrm{P}$ velocity structures of the lithosphere beneath Taiwan from the analysis of TAIGER and related seismic data sets. J. Geophys. Res., 117, B06306, doi: 10.1029/2011JB009108. [Link]

Lin, A. T. and A. B. Watts, 2002: Origin of the West Taiwan basin by orogenic loading and flexure of a rifted continental margin. J. Geophys. Res., 107, ETG 2-1-ETG 2-19, doi: 10.1029/2001JB000669. [Link]

Lin, A. T., A. B. Watts, and S. P. Hesselbo, 2003: Cenozoic stratigraphy and subsidence history of the South China Sea margin in the Taiwan region. Basin Res., 15, 453478, doi: 10.1046/j.1365-2117.2003.00215.x. [Link]

Ma, K.-F., J.-H. Wang, and D. Zhao, 1996: Three-dimensional seismic velocity structure of the crust and uppermost mantle beneath Taiwan. J. Phys. Earth, 44, 85-105, doi: 10.4294/jpe1952.44.85. [Link]

Rau, R.-J. and F. T. Wu, 1995: Tomographic imaging of lithospheric structures under Taiwan. Earth Planet.Sci. Lett., 133,517-532, doi: 10.1016/0012-821x(95)00076o. [Link]

Roecker, S. W., Y. H. Yeh, and Y. B. Tsai, 1987: Threedimensional $\mathrm{P}$ and $\mathrm{S}$ wave velocity structures beneath Taiwan: Deep structure beneath an arc-continent collision. J. Geophys. Res., 92, 10547-10570, doi: 10.1029/ jb092ib10p10547. [Link]

Seno, T., 1977: The instantaneous rotation vector of the Philippine Sea plate relative to the Eurasian plate. Tectonophysics, 42, 209-226, doi: 10.1016/00401951(77)90168-8. [Link]

Sun, S.-C., 1982: The Tertiary basins of offshore Taiwan. In: Salivar-Sali, A. (Ed.), Proceedings of the Second
ASCOPE Conference and Exhibition, Technical Programme Comm., Manila, Philippines, 125-135.

Suzuki, J., 1980: Introduction to Geophysics, Fifth Edition, Asakura Bookstore, Tokyo.

Wang, H.-L., L. Zhu, and H.-W. Chen, 2010: Moho depth variation in Taiwan from teleseismic receiver functions. J. Asian Earth Sci., 37, 286-291, doi: 10.1016/j. jseaes.2009.08.015. [Link]

Wang, Z., D. Zhao, J. Wang, and H. Kao, 2006: Tomographic evidence for the Eurasian lithosphere subducting beneath south Taiwan. Geophys. Res. Lett., 33, L18306, doi: 10.1029/2006GL027166. [Link]

Wang, Z., Y. Fukao, D. Zhao, S. Kodaira, O. P. Mishra, and A. Yamada, 2009: Structural heterogeneities in the crust and upper mantle beneath Taiwan. Tectonophysics, 476, 460-477, doi: 10.1016/j.tecto.2009.07.018. [Link]

Wu, F. T., R.-J. Rau, and D. Salzberg, 1997: Taiwan orogeny: Thin-skinned or lithospheric collision? Tectonophysics, 274, 191-220, doi: 10.1016/s00401951(96)00304-6. [Link]

Wu, Y.-M., C.-H. Chang, L. Zhao, J. B. H. Shyu, Y.-G. Chen, K. Sieh, and J.-P. Avouac, 2007: Seismic tomography of Taiwan: Improved constraints from a dense network of strong motion stations. J. Geophys. Res., 112, B08312, doi: 10.1029/2007JB004983. [Link]

Wu, Y.-M., J. B. H. Shyu, C.-H. Chang, L. Zhao, M. Nakamura, and S.-K. Hsu, 2009: Improved seismic tomography offshore northeastern Taiwan: Implications for subduction and collision processes between Taiwan and the southernmost Ryukyu. Geophys. J. Int., 178, 10421054, doi: 10.1111/j.1365-246x.2009.04180.x. [Link]

Yeh, Y.-H. and H.-Y. Yen, 1992: Bouguer Anomaly Map of Taiwan, Inst. Earth Sciences, Academia Sinica, Taipei City, Taiwan.

Yen, H.-Y. and H.-H. Hsieh, 2010: A study on the compatibility of 3-D seismic velocity structures with gravity data of Taiwan. Terr. Atmos. Ocean. Sci., 21, 897-904, doi: 10.3319/TAO.2010.03.03.01(T). [Link]

Yen, H.-Y., Y.-H. Yeh, and C.-H. Chen, 1994: Gravity terrain corrections of Taiwan. Terr. Atmos. Ocean. Sci., 5 , 1-10, doi: 10.3319/TAO.1994.5.1.1(T). [Link]

Yen, H.-Y., Y.-H. Yeh, C.-H. Lin, K.-J. Chen, and Y.-B. Tsai, 1995: Gravity survey of Taiwan. J. Phys. Earth, 43, 685-696, doi: 10.4294/jpe1952.43.685. [Link]

Yen, H.-Y., Y.-H. Yeh, and F. T. Wu, 1998: Two-dimensional crustal structures of Taiwan from gravity data. Tectonics, 17, 104-111, doi: 10.1029/97tc02697. [Link]

Yu, S.-B. and Y.-B. Tsai, 1981: Geomagnetic investigations in the Pingtung plain, Taiwan. Bull. Inst. Earth Sci. Acad. Sin., 1, 189-208.

Yu, S.-B., H.-Y.Chen, and L.-C. Kuo, 1997: Velocity field of GPS stations in the Taiwan area. Tectonophysics, 274, 41-59, doi: 10.1016/s0040-1951(96)00297-1. [Link] 